\title{
NEARCHOS. Networked Archaeological Open Science: Advances in Archaeology Through Field Analytics and Scientific Community Sharing
}

\author{
Nicolò Marchetti ${ }^{1}$ Ivana Angelini ${ }^{2}$ - Gilberto Artioli ${ }^{2}$. \\ Giacomo Benati $^{1}$ - Gabriele Bitelli ${ }^{3}$ - Antonio Curci ${ }^{1}$ Gustavo Marfia ${ }^{4}$. \\ Marco Roccetti ${ }^{5}$
}

Published online: 13 November 2017

(C) The Author(s) 2017. This article is an open access publication

\begin{abstract}
The full release and circulation of excavation results often takes decades, thus slowing down progress in archaeology to a degree not in keeping with other scientific fields. The nonconformity of released data for digital processing also requires vast and costly data input and adaptation. Archaeology should face the cognitive challenges posed by digital environments, changing in scope and rhythm. We advocate the adoption of a synergy between recording techniques, field analytics, and a collaborative approach to create a new epistemological perspective, one in which research questions are constantly redefined through real-time, collaborative analysis of data as they are collected and/or searched for in an excavation. Since new questions are defined in science discourse after previous results have been disseminated and discussed within the scientific community, sharing evidence in remote with colleagues, both in the process of field collection and subsequent study, will be a key innovative feature, allowing a complex and real-time distant interaction with the scholarly community and leading to more rapid improvements in research agendas and queries.
\end{abstract}

Nicolò Marchetti

nicolo.marchetti@unibo.it

1 Department of History and Cultures, Alma Mater Studiorum - University of Bologna, Piazza S. Giovanni in Monte 2, 40124 Bologna, Italy

2 Department of Geosciences, University of Padua, Via Gradenigo 6, 35131 Padua, Italy

3 Department of Civil, Chemical, Environmental, and Materials Engineering, Alma Mater Studiorum - University of Bologna, Viale del Risorgimento 2, 40136 Bologna, Italy

4 Department for Life Quality Studies, Alma Mater Studiorum - University of Bologna, Corso D’Augusto 237, 47921 Rimini, Italy

5 Department of Computer Science and Engineering, Alma Mater Studiorum - University of Bologna, Mura Anteo Zamboni 7, 40126 Bologna, Italy 
Keywords Digital archaeology · Open access · Data sharing · Cyber-infrastructure · Archaeological method and theory

\section{Introduction}

Archaeology is a systematic search for knowledge about the past through the study of the material correlates of the past. Fieldwork data are used for building interpretations of past social dynamics, both in the field and afterwards. The process consists of many steps of repeated standardized operations characterized by some degree of consistency. Digging and recording in archaeology involve unearthing, observing, and interpreting material remains (Hummler 2014).

Within this process that mixes subjectivity and objectivity, accuracy is measured in terms of the traceability of each step and in the richness of the recorded evidence. Since the digging of archaeological remains is not repeatable, it is obviously crucial that the recording operations are as accurate as possible. Scientific replicability in this field is guaranteed uniquely by the access to primary data (Atici et al. 2013, p. 678).

At present, the stages of this process are not recorded in full, and primary data are seldom if ever published integrally (Kintigh et al. 2014). An excavation is a destructive as well as a unique operation, and the interpretation of the excavator, albeit a necessary task, is not the only one possible. A fresh analysis should be carried out on the basis of all recorded data (Roosevelt et al. 2015), but in fact an excavation report is almost never an integral one. This hampers the quality of the reevaluation of a unique piece of information, the archaeological context, which is a quintessential epistemological operation since research goals and techniques are always changing.

Excavation teams are becoming increasingly multidisciplinary, and the contribution of technology to every step of the excavation and recording process is growing exponentially. In particular, digital and portable technologies are effectively changing the pace and accuracy of some of the steps of the digging process, such as the use of drones and laser scanners for surveying and photogrammetry or archaeometric and chemical analyses of finds. Thus multidisciplinary research teams produce highly differentiated datasets (paper files, digital files, databases, etc.), of which only a small part is formally disseminated (Kansa and WhitcherKansa 2013).

The digital and web-based revolution that we are, in general, experiencing in science has not yet considerably impacted the dissemination of archaeological datasets, which still relies on the production of written publications in which only a small selection of the data produced is represented. Furthermore, at present, there are no readily available protocols or infrastructures for integrating and interconnecting in a meaningful way the widely different datasets that are produced in the field.

The application of digital technologies coupled with the Open Data and Open Science approaches to field archaeology has several positive correlates: cutting costs and lags in producing traditional publications while keeping high-quality standards, 
reducing the gap between data acquisition and dissemination, providing the means to publish in full and share complex archaeological datasets, and obtaining real-time feedback.

We advocate that a digital, networked, and open field archaeology is what we need to make archaeology a sustainable, performing, and agile social science in the 21 st century. Here we propose an open approach-which we call the NEARCHOS approach: Networked Archaeological Open Science-to the creation, integration, discussion, and dissemination of archaeological datasets from multidisciplinary field research (and we do not dwell here on defining issues aptly raised by Smith 2017). Consequently, we first review recent developments in archaeological practices and academia, and then we propose a set of strategies that can be of help in enhancing data recording in the field and openly elaborate and disseminate the results via the web.

\section{Current Best Practices and Trends}

In recent decades, rigorous methodologies for analyzing past dynamics have been developed by means of a scientific epistemology and scientific techniques (Smith et al. 2012). Data recording and elaboration techniques have been updated exponentially in the last decade, mainly thanks to increasingly affordable and diffused digital and 3D technologies (Giligny et al. 2015; Roosevelt et al. 2015). In addition, the sophisticated application of methods from informatics and natural sciences has become crucial for building reliable models of past economic phenomena, to infer the places of origin of raw materials, reconstruct ancient technologies, and date sites and artifacts (Killick 2015, p. 242; Smith et al. 2012, p. 7617).

From a theoretical perspective, there has recently been an attempt at systematizing archaeological field practices and interpretation processes, the so-called "reflexivity" trend (see Berggren 2014; Londoño 2014). Reflexivity approachesboth theoretical and as applied field practices (at Çatalhöyük in Turkey and the city tunnel project in Malmö, Sweden [Berggren 2014, p. 6254])—-target the role of archaeologists as producers of data and the context of data production and interpretation in the field. By focusing on finding ad hoc solutions for enhancing data recording and interpretation in the field, we can, at least, try to mitigate the shortcomings that result from archaeological fieldwork and to elaborate strategies that are continuously in tune with the needs and constraints of excavation teams in their daily work. This is particularly important since, as stated above, field archaeology is becoming more and more multidisciplinary. Reflexivity approaches put to the fore the idea that interaction between specialists and excavators in the field should be a close and continuous flow of information. Of this trend, we stress particularly the importance given to shortening the distance between laboratories and excavation areas, and we propose below a series of ideas that aim at integrating these different aspects through a new learning structure.

Nevertheless, field archaeology is still generally performed according to traditional paradigms. Data recording practices generally used in the field are a 
mixture of analog and digital techniques that are affected by limitations and subjectivity at every stage (Roosevelt et al. 2015). Each step requires skills and accuracy that are often undercut by contingent or logistic reasons (cost-efficiency, time saving, subjectivity, environment, etc.).

\section{Partiality No More}

As stated in a recent manifesto article (Kintigh et al. 2014), many cultural processes involve nonlinear relationships in which cause and effect are not readily distinguishable. Consequently, a rich understanding of the past requires sophisticated interpretative strategies built on fine-grained primary datasets from systematic archaeological fieldwork. This can be made possible only if data are recorded and published in full. Kintigh et al. (2014) conclude their article stating that sophisticated archaeological research is hindered by the diffused unavailability of contextual information since primary datasets remain largely unpublished or not available online. To this we add that, if data are recorded traditionally, only a small subset of the information is available to other researchers.

There are three main correlates to this situation. The first is epistemological; research questions cannot be fully singled out (and answered) without full access to primary data. The second is ethical. Because most archaeological excavations are carried out with public funds, ethical issues can arise from the withholding of data. The third is operational: academic publishing is slow, costly, and requires an enormous amount of work (as well as extra funding, personnel, equipment, facilities) for converting analog data into digital and then paper formats (not to speak of readers who must, on an individual basis, convert paper contents into digital archives back again in order to make a systematic use of them).

As do other disciplines in the research and academic worlds, archaeology still relies almost totally on publications as a way to disseminate knowledge and achieve career advancement (Fig. 1; Kansa and Whitcher-Kansa 2013). Printed publications, consisting most often of secondary datasets, may take years to reach interested researchers who are not always able to keep pace with the growing mass of relevant literature (even when they are in pdf format, since they need to become part of the citation basis). At the same time, another important barrier is the availability and high price of specialized publications (Smith 2014). This outcome is ethically unacceptable, since we deal, in most cases, with research carried out with public funding. Open access commercial publishing moves part of the problem upstream, requiring authors to expend more-or-less substantial additional financial investments in order to publish.

In addition, traditional publishing-be it paper-based, e-book, or digital open access - still responds to a logic of selectivity in presenting the materials (i.e., the personal preferences of the excavator, time, and cost-saving variables, among others). This logic could be justified in the pre-digital era by production costs, but now it represents a self-imposed reduction in the presentation of the recorded evidence. Even in the pre-digital era, archaeologists did attempt to produce outputs different than the book/journal format, obtaining in some cases results comparable 


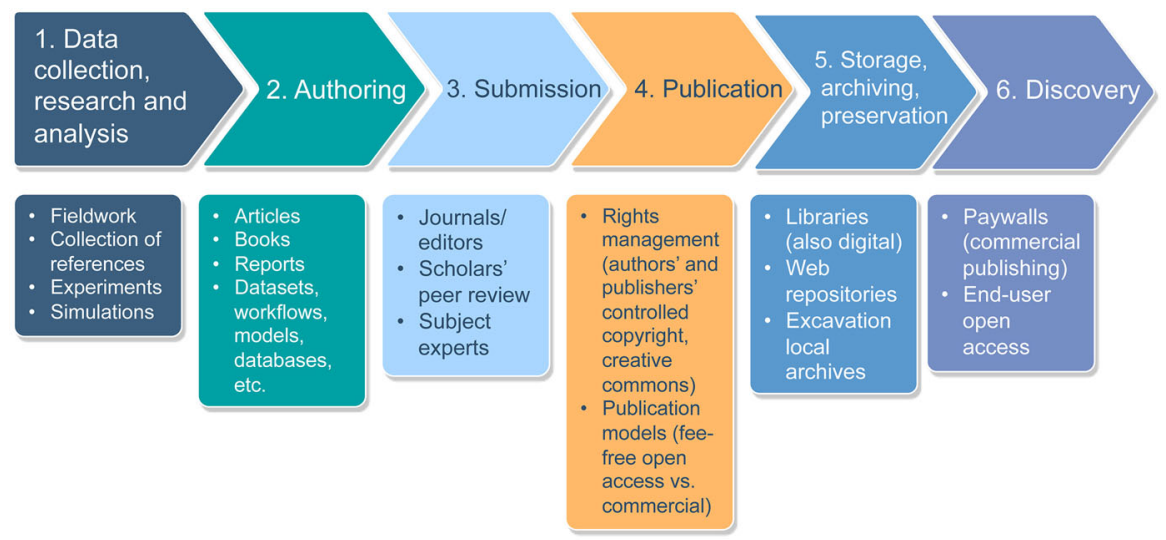

Timeline

Fig. 1 Current research and dissemination cycle

to modern databases - for example, the Human Relations Area Files or the research of Gardin (1956, 1958, 1976, 1978; see also Dallas 2016). These experiments certainly had an impact on systems of data organization, leading to the creation of digital databases, but they did not change data dissemination practices in archaeology.

It is a truism that traditional archaeological research is becoming less and less sustainable (e.g., Kansa and Whitcher-Kansa 2013, p. 95). New questions, entailing the search for new kinds of data, are defined in the scientific and academic workflows after previous results have been disseminated and discussed within the scholarly communities; if the stages of the process are lagged and datasets always partial, then progress is slow and the knowledge produced is heavily biased.

Digital humanities initiatives and web-based approaches are effectively changing the way that data are produced and reused in the realm of cultural heritage (Kansa et al. 2011; Snow et al. 2006) and also in scholarly publishing and dissemination of knowledge in all fields. The use of digital data for archiving, managing, and conserving cultural heritage is growing exponentially (see, for example, the Journal of Heritage in the Digital Era, the Digital Applications in Archaeology and Cultural Heritage website, the Open Context project; Table 1). Of course, the production of large collections of digital data also poses problems of structure, access, and longterm preservation, given the tendency of electronic technologies to become obsolete relatively quickly. Numerous projects and online services have been created in the last few years to ensure quality, availability, and long-term storage of digital archaeological datasets. Repositories such as tDAR (The Digital Archaeological Record), Digital Antiquity, and Archaeology Data Service (ADS) aim at storing, curating, and preserving digital datasets and also broadening their access (but with high maintenance costs).

Although very promising, these advances require organized digital collections that are simply lacking for many past and present excavations, large funds, and the 
Table 1 Web projects and sites with their respective URLs

\begin{tabular}{|c|c|}
\hline Project cited in the paper & URLs \\
\hline $\begin{array}{l}\text { American Historical Association Digital } \\
\text { Publication guidelines }\end{array}$ & $\begin{array}{l}\text { https://www.historians.org/teaching-and-learning/ } \\
\text { digital-history-resources/evaluation-of-digital- } \\
\text { scholarship-in-history }\end{array}$ \\
\hline Arcadia Fund & $\begin{array}{l}\text { http://www.arcadiafund.org.uk/media/5454/open- } \\
\text { access.pdf }\end{array}$ \\
\hline Archaeology Data Service (ADS) & http://archaeologydataservice.ac.uk \\
\hline ARIADNE project & http://www.ariadne-infrastructure.eu \\
\hline arXiv & https://arxiv.org \\
\hline \multirow[t]{3}{*}{ Community Research tools } & https://polymathprojects.org \\
\hline & http://www.crawdad.org \\
\hline & http://www.orbit-lab.org \\
\hline Digital Antiquity & https://www.digitalantiquity.org/ \\
\hline $\begin{array}{l}\text { Digital Applications in Archaeology and } \\
\text { Cultural Heritage }\end{array}$ & $\begin{array}{l}\text { http://www.journals.elsevier.com/digital-applications- } \\
\text { in-archaeology-and-cultural-heritage/ }\end{array}$ \\
\hline ERC Open Access policies and guidelines & $\begin{array}{l}\text { https://erc.europa.eu/funding-and-grants/managing- } \\
\text { project/open-access }\end{array}$ \\
\hline Human Relations Area Files & http://hraf.yale.edu \\
\hline Journal of Heritage in the Digital Era & http://www.multi-science.co.uk/ijhde.htm \\
\hline $\begin{array}{l}\text { National Endowment for the Humanities Open } \\
\text { Government and Open Data policies }\end{array}$ & https://www.neh.gov/about/legal/open-government \\
\hline $\begin{array}{l}\text { National Geographic Space Archaeology } \\
\text { Project }\end{array}$ & $\begin{array}{l}\text { http://nationalgeographic.org/projects/space- } \\
\text { archaeology/ }\end{array}$ \\
\hline Open Context Project & https://opencontext.org \\
\hline Open Science Framework & https://cos.io/our-products/open-science-framework/ \\
\hline SocArXiV & https://osf.io/preprints/socarxiv \\
\hline $\begin{array}{l}\text { Society of American Archaeology's Open } \\
\text { Science Interest Group }\end{array}$ & https://osf.io/2dfhz/\# \\
\hline Stanford Forma Urbis Project & http://formaurbis.stanford.edu/index.html \\
\hline The Digital Archaeological Record (tDAR) & http://core.tdar.org \\
\hline Çatalhöyük project database & http://www.catalhoyuk.com/research/database \\
\hline
\end{tabular}

will to make archaeological datasets available to the public. For these and other reasons, at present, excavations teams that adopt these services are exceptions.

\section{Going Open}

Within this rapidly evolving landscape, Open Access, Open Data, and Big Data approaches are hot topics that, however, still remain at the margins of archaeological practice (Kansa 2012). To change the scholarly information infrastructure, we need to apply not only new forms of data recording but also change dissemination practices. The use of modern digital media has the power to do so 
only if we apply an open perspective. We believe that Open Data and Open Methods, entailing online digital publication of primary datasets, can have an enormous impact on how data are created in the field and how they are reused by the scholarly community to build new research (e.g., Marwick et al. 2017; Wilson and Edwards 2015).

Our baseline assumption is that we need to record data more consistently in the field and to release them in full as structured open data since archaeological excavations are a public good that should be shared, and the primary data from the excavation are necessary for making advancement in the discipline (Atici et al. 2013; Kansa and Whitcher-Kansa 2013). Scientific elaboration is hampered not only by limited access to research data but also by the fact that, in most cases, the data are not ready for digital processing. This entails the need for vast, costly data input and adaptation, and even more when several different publications are involved.

Born-digital and encoded data can improve access to scholarly content, that in turn allows researchers to cut costs, make easier, faster, and more productive research and teaching material, obtain higher citation rates, and overall make it easier to transfer knowledge between sectors (see the Open Access manifesto by the Arcadia Fund). In this light, we stress two trends. First, more and more research is conducted online. Second, academic research is becoming increasingly collaborative. The rapid change in participation in academic social media and the need for online access to archaeological datasets also should be taken into consideration. The online dissemination of scholarly content and search for online peer review (Academia.edu, ResearchGate.net, Google Scholar, in addition to online repositories such as JSTOR) increased enormously in the last years. Furthermore, much cultural heritage already has been turned into digital collections (virtual museums, digital libraries, scientific repositories), making the production of digital data an asset for cultural data documentation, management, and conservation (Ikeuchi and Miyazaki 2008).

Beyond archaeology, a case that deserves mention is the Polymath Project created by a group of mathematicians who collaborate online to solve open mathematical problems (Cranshaw and Kittur 2011). The Polymath blog has shown that problems can be solved quickly through a collaborative web-based approach. Problem solving through communal effort and discussion is more efficient since it hinges on the availability of more people and different skillsets. The Polymath project also demonstrated that participation needs to be incentivized by affording proper academic attributions to the contributions of individual scholars. A digital open and networked science therefore entails that data sharing should be encouraged and online contributions should receive academic credit.

In computer science, it is possible to access resources shared by specific groups, resources that are then put to good use by other research labs to generate new findings and research reports (CRAWDAD, Orbit-Lab, see Table 1). Excavations, due to their unique peculiarities, pose even more challenging and interesting research problems; here the "real-time" variable could really be the most important and innovative part, even when compared to other disciplines. The Open Data model is still struggling to receive validation in archaeology since jobs and career advancement are awarded on the basis of research published in traditional venues. 
New criteria for allocating credit for the production and reuse of digital data-for example, metadata with embedded authorship, as proposed by the ARIADNE project; extensive use of DOIs linking publications and primary data; or the "one URL per potsherd" model proposed by Open Context — should be evaluated in order to make the open release of primary digital data the customary output of archaeological excavations (the "data sharing as publication" model, Kansa and Whitcher-Kansa 2013, p. 89). The guidelines for evaluation of digital scholarship, recently issued by the American Historical Association (June 2015; see Table 1), are a positive example; they do not, however, move past a formal commitment to equate paper-based and digital publications (see also the ERC and NEH Open Data/ Open Access policies in Table 1).

We advocate that open digital data policies should be elaborated by funding bodies in relation to field archaeology. Data sharing, reuse, and collaboration should be considered not only as criteria for awarding research grants but also for contributing to academic advancement. Appropriate metrics, the tracking of data reuse, and new policies for peer review of digital contents should be elaborated for awarding credit and for encouraging production of digital media.

Employing sophisticated technologies is only functional and subservient to operational protocols to be applied in the field, so a different attitude about how to carry out field research for generating an information flow within a networked environment, enhancing data elaboration, and their evaluation needs to be adopted. Online full, real-time, and free dissemination is a requirement, but, of course, a new information architecture must be designed; the book/journal format that we are all familiar with must be reworked into a format appropriate to a digital interactive environment.

Networked elaboration and consistent access to data will help bring forward research questions that may be tested and validated in the field together with those that arise during first-stage research. It thus becomes possible to radically change the way that archaeologists work in the field and how data are produced, the way that archaeologists elaborate their datasets, and the way that fruitful scientific criticism can be incorporated into ongoing projects.

\section{Short-Circuiting Field Archaeology}

Better science is made by singling out new research questions, leading to the production of new, different data. To do so, we have to operate at two distinct, yet interrelated levels: data production and data dissemination and evaluation. We need to apply the Open Knowledge approach (e.g., Molloy 2011) to field archaeology in order to pursue a more global view of the excavation process. The ultimate goal of this approach is to build a new architecture of knowledge for field archaeology through a new learning strategy.

First, as a set of routine applications in the field, we should use digital surveying and recording techniques, carrying out at the same time a wide array of scientific analyses almost in real time, by bringing laboratories to excavation areas. Having readily available information from sampling may allow archaeologists to assess 
excavation and sampling strategies accordingly during fieldwork, significantly reducing post-excavation processing and data elaboration. This is achievable by experimenting with portable technologies to reduce the gap between data extraction and analysis. Advanced techniques for fieldwork comprise digital photogrammetry, microstratigraphy and micromorphology, systematic soil sampling, and chemical/ mineralogical analysis of the finds.

Complex contextual information and multidisciplinary datasets from this array of analyses are difficult to manage both with traditional methods and in digital format. Digital data require specific digital environments for proper display, integration, and exploitation. Traditional publications in paper and/or pdf are not adequate formats for displaying digital datasets: what is the utility of building a complex 3D model if the only published outcome of this effort is a small black/white screenshot on the page of a journal? The same can be extended to databases, flowcharts, videos, GIS files, agent-based modeling, and so forth.

Meeting these needs requires cyber-infrastructures (Kintigh et al. 2015) to record the full array of data produced in the field as born-digital data and to publish openly the primary information on the web. We consider data sharing as a form of publication. To this end, digital datasets, models, databases, and instrument logs should to be shared on the web and published in full through preliminary reports (or technical reports). Digital data need to be freely usable but marked by DOIs and encoded authorship information to give academic credit to the producers.

Open access policies need to be implemented not only in post-processing but also from the very inception of a project. This approach will result in web-based projects in which linked and integrated information from all disciplines concerning the excavation can be managed through open source software adapted and developed for the project.

Then, a second new scholarly behavioral step needs to take place. Sharing evidence remotely in real time with colleagues, both in the process of field collection and subsequent study, may represent a key innovative feature for field archaeology (in a way that can be somehow compared to contemporary "live surgeries" in medical sciences). This will allow real-time remote interaction with the scholarly community, leading to rapid improvements in research agendas and queries. The by-product of this data-sharing mode will be the modifications of researchers' behaviors. Making available complete datasets from archaeological excavations, both as raw and refined data, in a single searchable platform will speed up scholarly work significantly.

We believe that a stream of uninterpreted data may have represented a relatively insurmountable problem until some years ago, since there was no way to process and analyze large amounts of unstructured (and analog) information in a timely manner. This barrier no longer exists today, as demonstrated by the "big data" approaches (Kitchin 2014). It also is possible to imagine that, ideally, more and more opportunities to process increasingly large and complex amounts of digital data will arise in the future, making big data analysis a key rationale in archaeology.

We are confident that this approach will make archaeology more cost-effective and tuned with the speed of contemporary developments. Freely usable digital data then will enhance the fruition of the information retrieved through digging and will 
provide a competitive advantage for creating new knowledge, new research questions, and overall a more articulated understanding of the past. Our hope is that this contribution will stimulate alternative production of data (a better descriptive term than collection) within explanatory pathways generated by community-based scientific forums (a process that we call the NEARCHOS approach).

\section{Open Strategies for a Networked Field Archaeology}

Here we review a series of techniques and strategies that, if applied consistently in the field, have the power to change the pace and accuracy of data collection and recording procedures, enhancing all four domains of archaeological recording (Hummler 2014, p. 6241): location (position), elements observed and not kept (strata), elements kept (finds, samples), and monitoring (checking the recorded evidence). These techniques do not necessarily form a custom "package"; they can be scaled and customized according to particular needs, constraints, and budget that are singled out by each excavation team.

Open source software allows scholars to avoid the payment of costly licenses (ranging from hundreds to thousands of euros/dollars) and the limitations of lockedin propriety software, while retaining the quality of commercial software (although in some cases, with less user-friendly environments). Costs of digital devices vary widely, from a few hundreds/thousands of euros/dollars for drones, digital cameras, and portable scanners, to several tens of thousands of euros/dollars for the most upto-date portable devices; some of the strategies discussed below require an investment in equipment. This of course needs to be in line with the excavation strategies and goals devised by each team. However, if we couple open source software and low-cost digital devices, we can, on the one hand, obtain highresolution digital outputs that are, in most cases, almost publication ready and, on the other hand, dramatically cut costs and post-excavation processing workflows.

\section{Data Creation Strategies}

There are several techniques that may be used to structure the datasets that are created during fieldwork and then to disseminate them openly. Scientific analyses and digital, web-based technologies, and 3D tools (Minto and Remondino 2014) have the potential not only to overcome some of the flaws detailed above but also to greatly improve data recording operations in the field (Fig. 2). We can apply a truly holistic approach to field archaeology by targeting a complete interconnection between the study of the environment and artifacts.

There is no doubt that a steep learning curve may exist when new and different tools are employed during excavation. It also is true that in many cases this same problem is already present but simply is pushed out of mind, as very often some type of digitization is already integrated in the analysis of the finds. The downside of this second approach is that such processes are performed, in many cases, far from the excavation areas, and hence providing no opportunity for adjustments, integrations, and additional collection of information. The availability of analytical 

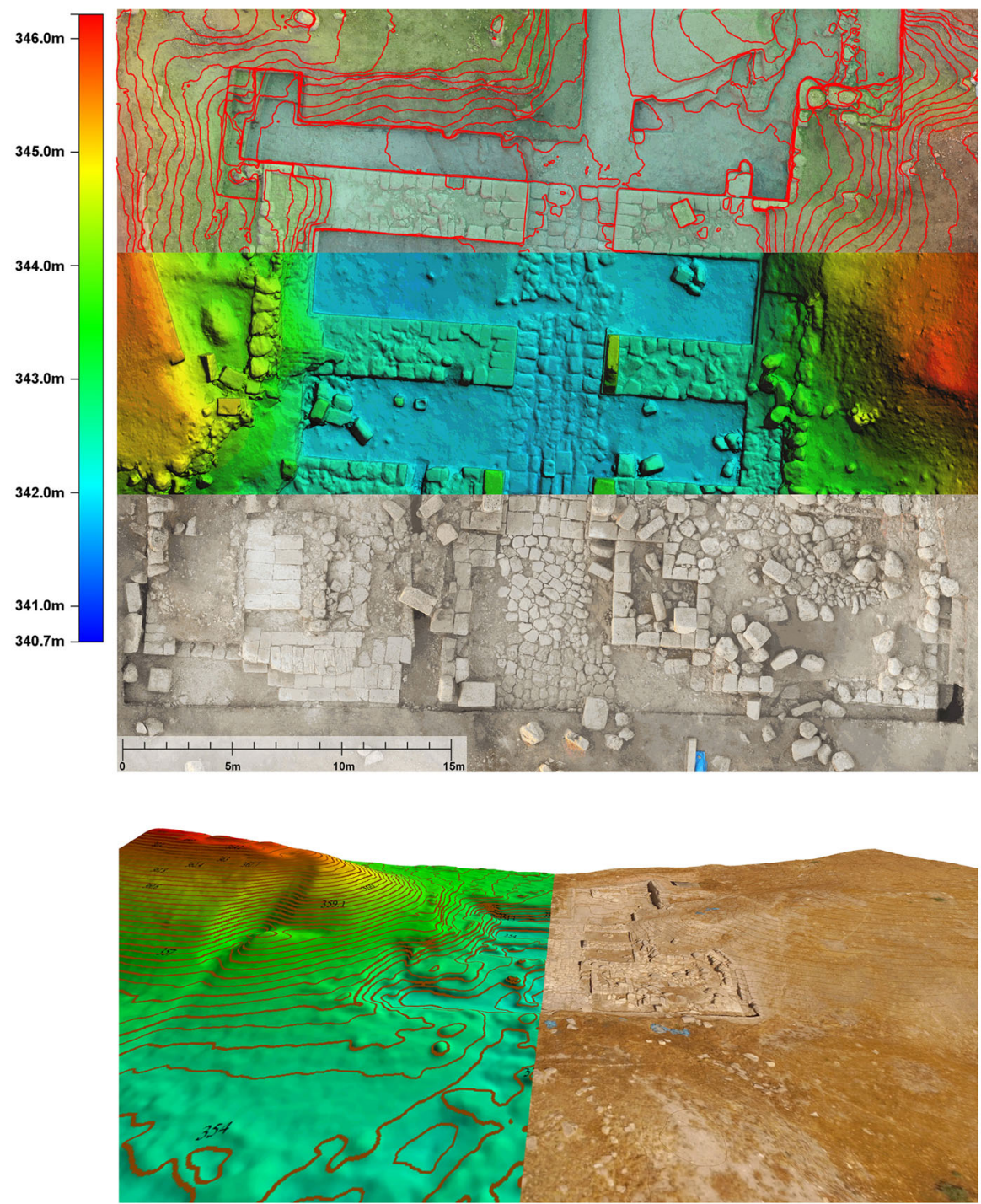

Fig. 2 Turning material evidence into digital: photogrammetric documentation of the South Gate from the Iron Age in the Inner Town at Karkemish, Turkey (courtesy of the Turco-Italian Archaeological Expedition at Karkemish)

data during excavation and the improvement of user abilities in the field may help the directing/managing of the excavation itself and even provide key parameters to confirm or modify the strategy of archaeological fieldwork.

Another important step forward would be the reduction of the distance between labs and the field. Setting up field labs equipped to perform a broad range of analyses (preliminary and definitive) and to make steady use of portable instruments should become a standard requirement. By bringing experts (with their instruments) 
closer to the field, it is possible to curtail the learning curves for the scientific tools, to reduce equipment costs for the excavation team, and to have readily available (preliminary) results from analyses in the field, the quality of which is controlled by experts.

We believe the data from excavation, surveys, and scientific analyses should be stored, interconnected, and managed through e-infrastructures and shared online in order to openly disseminate the datasets created and get feedback in real time, both from different members of the excavation team and from external experts. Interaction and discussion during the excavation process ought to be increased. At present, there is no readily available protocol for doing so, but several research teams are heading toward this very goal. Significant headway has been made by teams working at Çatalhöyük (Berggren et al. 2015; Forte et al. 2012), Kaymakçı in Turkey (Roosevelt et al. 2015), and Pompeii in Italy (Dell'Unto et al. 2016), among others. The systematic use of digital and 3D technologies through the recording process positively impacted the in-field praxis in the above-mentioned endeavors, greatly improving the amount and accuracy of data obtained from the excavations (see Fig. 2). The creation of GIS files incorporating 3D features and integrating digital models of the excavated features with databases containing spatial, artifactual, and stratigraphic data are some of the most promising results from these experiments.

These achievements are a turning point for practices in the field since they provide protocols and cost-effective techniques for considerably improving not only data recording but also access to excavation data, visualization, and research. We need to build on these successful experiments and make systematic use of a 3D archaeological approach throughout all stages of the excavation process. To do so, digital technologies need to be applied consistently and new learning frames need to be built.

Two methodological domains are affected by this approach. The first is digital documentation of the digging process. Digital photogrammetry tools provide the means to create, almost in real time and with relatively cheap instruments, highprecision 3D models (digital surface models, or DSMs), allowing the creation of a digital history of the progress of the excavation through time (e.g., Berggren et al. 2015; Doneus and Neubauer 2006; Forte 2014). WebGIS architectures allow the creation of integrated platforms for storing and handling large archives of georeferenced data, be it geographical, contextual, artifactual, or ecofactual, linked with OS 3D web players. Time-resolved segmentation of the excavation "movie" should produce a dynamic picture of the investigated architectural and landscape environments and yield a far better contextualization of the excavated finds and the related human activities.

The second is the filing of finds and archaeological units. High-resolution images and 3D models allow archaeologists to measure automatically the morphological characteristics of the finds, replacing analog approaches, eliminating subjectivity from the process, and ultimately compressing post-processing times (e.g., Roosevelt et al. 2015, p. 227). Data extracted in this way can be exported in a variety of formats, making possible web exploration, the creation of online catalogs, virtual museums, and even replicas with 3D printers (e.g., the Stanford Forma Urbis 
Project). Systematic campaigns of micromorphological analyses can be used to characterize scientifically the deposits that form the stratigraphic sequence (in terms of granulometry, color, compactness, etc.), limiting the pitfalls generated by visual determination of depositional units. To go beyond the visual approach to a quantitative characterization of materials, we add the archaeometric dimension to the study of these features.

A range of techniques and methodologies can be implemented in the field to meet the requirements presented above. The first, although not yet fully developed, is $3 D$ GIS architecture for recording activities and finds in the field. One of the main tasks in rethinking archaeological fieldwork is that of designing a cyber-infrastructure capable of managing the complete pipeline of data collection in the field and the sharing and mining of data for research (Snow et al. 2006). The main objective here is to fully integrate artifactual and contextual information with $3 \mathrm{D}$ infographic representations of the excavated features, possibly within a 3D GIS architecture. These can be georeferenced and interconnected with finds, archaeological features, and stratigraphic units to make possible and practical data retrieval and filtering. The platform should be capable of handling geographic features and allow queries and spatial analyses, supporting multi-user access and interaction and automatic metadata extraction from both born-digital data and digitized paper-based literature.

This will not only provide a fundamental tool for recording an excavation in greater detail (indeed, one day we will get a full 3D archive of the excavation process itself, which we can now get only at discrete time intervals), it also will considerably cut post-processing time and costs. The simple use of metadata and algorithms capable of grouping information based on such metadata (which, of course, implies raising questions about models and interrogation procedures) should facilitate queries and large-scale data mining immensely. The software infrastructure must be capable of supporting two coexisting requirements: real-time cooperation and interaction between on-the-field and remote researchers and still grant remote access to high-quality information.

High-definition $3 D$ shape acquisition systems allow rapid and precise measurement of the morphology of small-scale artifacts and high-quality virtual rendering (by means of laser scan, tomography, etc.). These techniques can be applied to document cultural artifacts, bioarchaeological deposits, and archaeological and landscape features (e.g., Jiménez Fernández-Palacios et al. 2014).

Another approach is photogrammetry, such as $3 \mathrm{D}$ digital surface models to systematically document the progress of excavation, landscape features, and monuments to create georeferenced time-tagged digital records of the excavation process. The 3D survey of the archaeological process allows us to better document structures, deposits, and finds, to reduce fieldwork time, and to improve the interpretation of archaeological materials. The data acquired via a 3D-modeling pipeline permit researchers to assess volumetric information for stratigraphy, the topographic position of the finds, and the correlation between spatially distant objects/points, and to gain a better understanding of the formation processes of the deposits and their excavation history over time (in fact, it is the contextual associations that define the functions of objects, which are given and not inherent, e.g., Appadurai 1988). 
Aerial and ground photogrammetric surveys, carried out through drones or telescopic rods, are processed with specific software to obtain point clouds or meshes (currently, our team at Karkemish, Turkey, can process an area of 0.5 ha in 6 hours from high-resolution photographs to the final textured 3D model). The resulting 3D hybrid model (i.e., terrain model plus archaeological or building structures) has embedded spatial, volumetric, and color/texture information. The outcome of this work is the production of high-precision 3D-textured models, almost in real time, significantly reducing the use of total stations and optimizing and speeding up operations in the field (Fig. 2). The joint application of photogrammetry and terrestrial 3D scanning, in this case, results in the detailed description of a given site at different scales, from large structures to small finds (i.e., micromorphology). Digital photogrammetry can be obtained from ground surveys or from cameras on drones; 3D scanning can be performed by different instrumentation, from terrestrial laser scanners to structured-light devices. These surveys have the potential not only to improve the acquisition of data but also to enhance interpretation of archaeological contexts and occupational phases through high-definition textured surface models. They can be used to document a variety of subjects: archaeological and landscape features, monuments, rock art, sculptures, degradation, collapses, etc. Aerial imagery from drones also allows us to obtain high-resolution imagery and topographical maps that can be used for a wide array of visual and machine-based interpretations (e.g., vector plots, orthophoto mosaics, or DSMs with texture mapping).

Remote sensing can be used to obtain multispectral/hyperspectral imagery at different spatial and spectral resolution. Image analysis provides elements to build a general frame for sites, to obtain a better characterization of landscape and materials, and to support new archaeological investigation in the areas of interest. Advanced processing procedures should be adopted for an effective data-fusion process, taking into account radiometric and geometric calibration workflows developed and tested in previous archaeological experiences (e.g., Lasaponara and Masini 2012). Optical and radar images can be used alternately or together, depending on the aims of the analysis and the environmental context; old declassified images can be furthermore adopted to provide background documentation for large areas and to analyze their evolution through time (Bitelli and Girelli 2009; Ur 2013). Airborne laser-scanning data can provide high-resolution and highprecision DSMs on larger areas to support the research before and during excavation; these kinds of data can be essential in forested areas (Doneus and Briese 2010).

Microstratigraphic sequences with traditional thin-section analysis coupled with portable probes such as confocal optical microscopy, Fourier-transform infrared spectroscopy (FTIR), and/or X-ray fluorescence (XRF) (e.g., Wilson et al. 2008) should be obtained from archaeological deposits in order to carry out micromorphological and pedological studies (Weiner 2010). This would allow a precise definition of the nature of the deposits, which is critical for a better definition of sedimentary, pedological, and anthropological processes that affected/created the archaeological deposits. 
Another important methodology involves systematic soil sampling for bioarchaeological remains. Today it is possible to develop new strategies to carry out and speed up systematic collection and analyses of bioarchaeological remains in the field. These include the systematic use of 3D digital and confocal microscopy to carry out microscopic-level analyses and 3D technologies ("structure from motion") to document the exact setting of finds in the field and create large databases of characterized materials and digital reference collection (Curci 2013; Fanti et al. 2015).

A final approach is the systematic archaeometric analysis of archaeological finds. Chemical, mineralogical, and physical characterizations of organic and inorganic finds are not only powerful analytical tools for assessing past activities, they also provide information critical for the proper excavation, interpretation, and conservation of excavated materials (Artioli 2010; Artioli and Angelini 2011; Pollard and Heron 2008). On-site analyses (optical microscopy and field instruments such as XRF, FTIR, X-ray powder diffraction [XRD], 3D digitization techniques) yield readily available information on the production and use of artifacts. This can help archaeologists working in the field to interpret more readily the features they are excavating and consequently to plan their excavation strategies more accurately. Cross-referencing archaeometric, bioarchaeological, and geological analyses in the field would greatly aid the efficient filing of archaeological finds. This procedure is, at the moment, a subjective and empirical process that relies exclusively on the intuition of the excavators. By obtaining early, precise distribution and characterization of finds, we can gather insights not only on depositional processes in their archaeological setting but also on manufacture and usage patterns. This procedure also will eventually allow us to overcome some of the flaws involved in the process of filing archaeological finds.

\section{Open Data Dissemination Strategies}

Here we discuss the dissemination of primary archaeological datasets. Digitally produced datasets should be handled mainly through web portals that grant access to the 3D GIS of the excavations (see below) and the digital reference collections that are created for characterized artifacts. All objects that are produced (datasets, workflows, models, images, etc.) should be structured and encoded with DOIs, authorship information, and other metadata.

As stressed by Kitchin (2014), the exponential growth in the production of digital data creates challenges related to the handling, processing, storing, and interpretation of the data. The problem is that as the amount of data increases enormously, the percentage of these data that gets analyzed and processed shrinks. Another issue is data quality; scarce or poor-quality data will definitely undermine research efforts and produce weak scholarship. In this light, data organization through coherent infrastructures and quality control become key requirements in the task of changing how we produce knowledge and disseminate the findings of archaeological research. The issue of data quality is vast and cannot be addressed properly in this paper (Kintigh et al. 2015, p. 10; Kitchin 2014); rather we concentrate on the creation of cyber-infrastructures for interconnecting and accessing fieldwork datasets. 
The ideal environment to interconnect all the data produced in the field is that of a GIS with 3D capabilities (e.g., Carver 2005). Spatial data and images can easily be integrated with other datasets from excavations, such as catalogs of archaeological finds and data from scientific analyses, by using GISs (e.g., Berggren et al. 2015, pp. 441-442; Landeschi et al. 2016). After the creation of intrasite 3D GIS systems, the next step is the creation of virtual research environments (VREs). The implications of creating and using VREs are two-fold: they can provide enriched datasets and interlinked data, and they can be used for real-time feedback, evaluation, and criticism from the scholarly community. Interaction with data and models is, in fact, crucial for the interpretation of the archaeological evidence.

VREs provide the means for publishing open digital datasets online and for obtaining real-time feedback between excavators and outside experts while the fieldwork is ongoing. In this light, solutions for creating networks of experts and scholars need to be explored and implemented (Fig. 3). The combination of e-infrastructure and optimized metadata will facilitate information retrieval, interpretation, and reuse of data by combining spatial and conceptual search parameters through a user-friendly interface (web portal). The creation of a VRE for data sharing and online collaboration at various levels, from streamlining work in the field to developing solutions to complex research problems, should become a standard output of digital archaeological endeavors. For this to happen, web tools

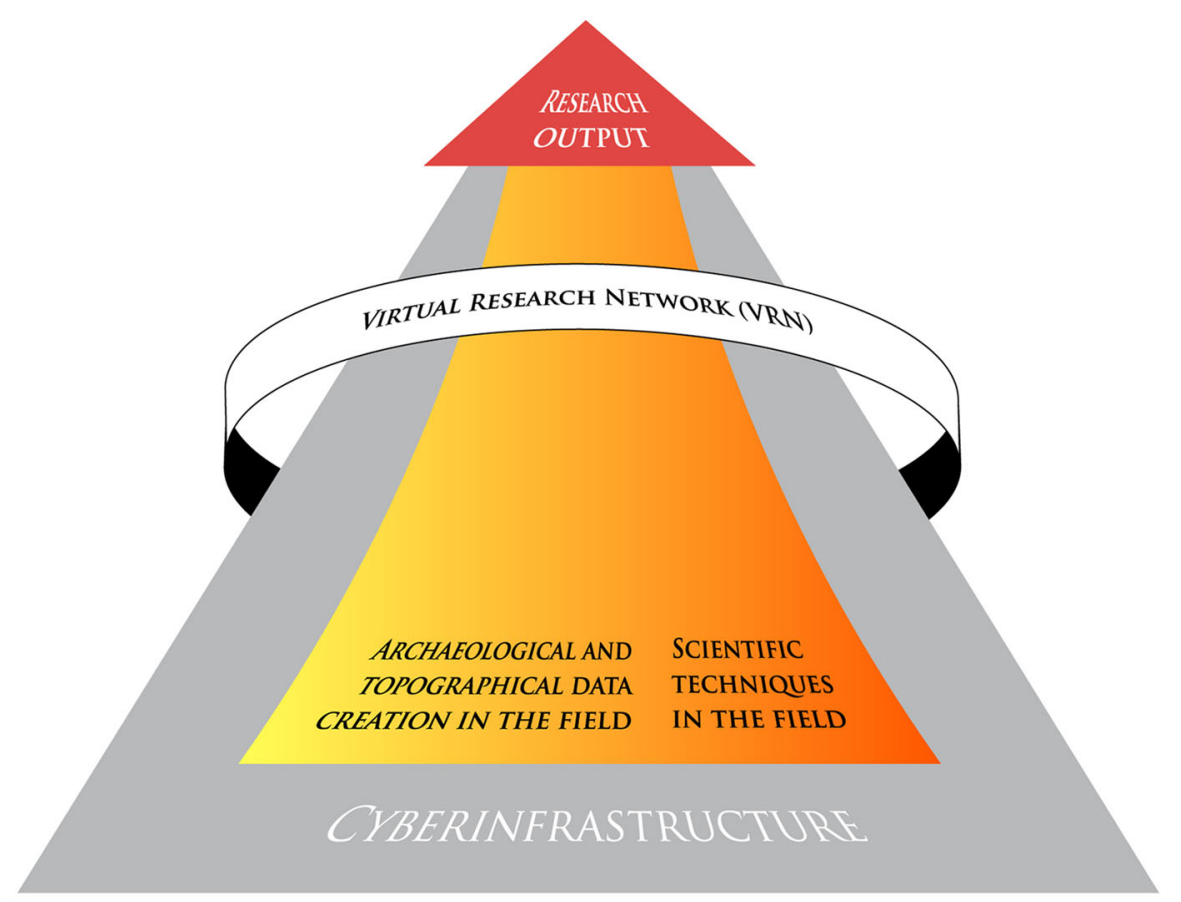

Fig. 3 Prospective digital pipeline of field archaeological research organized through a virtual research network 
and social academic media tools need to be explored and developed to create interactive structures, live feeds, review sessions, and annotated workflows.

Technical reports (with copyright, ID, DOIs, etc.) also may be used to share readily available primary data with the scholarly community. Following the example of the arXiv platform (Cornell University) for physics, mathematics, computer science, quantitative biology, quantitative finance, and statistics, the recently opened platform SocArXiV_connected to the Open Science Framework initiative-now provides a service for producing and openly sharing technical reports, papers, and datasets (with citation keys and indexed by Google Scholar) in the humanities and social sciences (see http://blogs.lse.ac.uk/impactofsocial sciences/2016/07/11/developing-socarxiv-an-open-archive-of-the-social-sciences/). Free and open technical reports/working papers/preprints are, in fact, widely used in the natural sciences and in some social sciences, such as economics, to promptly disseminate research results; they are relatively absent in archaeology. This model is intended not only to challenge the time lags and pay walls of academic publishing but also to stimulate feedback and criticism by specialists and eventually generate academic papers and further research. All considered, these platforms appear to provide ideal venues for sharing preliminary results and primary datasets from archaeological fieldwork and also the means for reliable citation and reuse of information, giving credit to individual contributors.

One problem that remains is quality control. Upon our enquiry with arXiv, the administrator so responded to us on August 23, 2016: "The creation of a new subject class requires considerable support from the community that will use it.... we require a commitment from a significant group of researchers to submit papers using the proposed subject class. This should include promises to submit a number of initial papers to get the subject class going. We also need a volunteer to moderate the class by reviewing daily submissions and flagging inappropriate submissions. This moderator should also review a significant number of already archived papers, looking for submissions that can be cross-listed to the new subject class and contact authors encouraging them to do so."

Repositories such as ArXiV.org-not unlike peer-reviewed journals-use moderators and scientific boards to evaluate submitted papers. But open reviews and open session tools also may be experimented with to involve specialists in reviewing the datasets that have been produced, thus curtailing the time-consuming and often one-sided/biased process of academic peer review.

We stress that VREs can be used following different dissemination strategies: the VRE can be restricted to team members, encompass a select group of external experts and scholars, or be selectively/completely open to the public. The selected strategy should take into account the needs of local communities that, in some cases, may not want to disseminate sensitive data (e.g., the location of burial grounds) to avoid the risk of looting (e.g., Mueller 2016). We note, however, that the most dramatic cases of looting, such as those carried out on the archaeological sites in southern Iraq between 2003 and 2007 (Emberling and Hanson 2008), exploited the weaknesses of local control, impunity for perpetrators, and strong market demand, and were not organized following any online data stream. 
On a more positive note, it is worth citing Çatalhöyük in Turkey, where a digital environment for direct engagement of small teams of researchers with models and datasets created in the field has been recently created through the means of immersive reality (Forte 2014, figs. 26-32). The main goal of this effort was to make the excavation process virtually reversible in a simulated environment. Immersive reality may represent one of the most groundbreaking applications for the study of archaeological data and, at the same time, provide the means for guiding the work of archaeologists in the field through a new type of interaction between excavators and networks of experts/scholars, based on a continuous feedback (e.g., Roosevelt et al. 2015, p. 341).

The visualization of data is, in fact, a very hot topic in all disciplines. It is worth mentioning that a high chance exists that, very soon, the way that we normally access imagery will probably change. It will soon be possible to navigate through $3 \mathrm{D}$ spaces relying on new advanced virtual reality technologies, as low-cost, highperformance, and head-mounted displays are expected to be on the market very soon (Salomoni et al. 2017). As they say, "an image is worth a thousand words," much the same way "a 3D voyage is worth a thousand images."

In essence, this technological shift will potentially pave the way to widespread access to 3D data for the dissemination and use of archaeological 3D models. This simply means that, for example, a movie could be seen with the eyes of an actor, or a soccer match from different points of view on the field. We cannot exclude today that something like this may happen, and it could be very useful for archaeological fieldwork and/or carrying out research based on it.

The discussion about data sharing among VREs and the public entails, albeit not as a core issue, the question of data durability and software obsolescence. This is, of course, a most significant matter due to the enormous efforts that have been poured into the digitization of data and the software architectures needed for managing them. Yet it is a question that does not have a direct bearing on our purpose, which is about creating new science through the collection and sharing of data within a relatively short time span.

Beyond limitations of codification, archaeological practices may rely on digital infrastructures whose hardware and software will ultimately wear down. Hence, there is an issue that the result of the digitization of those practices may not only change, but in some sense also deteriorate. Over time, we run the risk that future generations will no longer be able to access the data. Preservation in the digital realm may entail disruption and loss of data. From cave painting to cataloging, people have built cultural records of ritual activity and embodied knowledge. During the process of documentation, archaeologists code their data into imagery, text, tables, and audio to hold onto some aspects of their original appearance and throw away others. In this sense, the question of what to document and preserve (and how) should strike us as nothing new. Yet, with digitization comes something more. We have possibilities for learning and interacting that were not available before. Nonetheless, digitization comes at a cost: that of providing continuous effort toward the goal of adhering to digital format standards. If one wants to avoid the paradox of destroying finds by digital preservation, the research community should 
be committed to preserve standards and keeping them up to date (Rosner et al. 2014).

The use of open source software or fee-paying platforms that take care of conversion updates for hosted data like tDAR does, in fact, provide a certain degree of assurance about data durability and accessibility. The key factor is that data should not be abandoned in a virtual box but constantly cared for by a system manager. Data perusal and exploration must be ensured by constant data availability and access. Free cloud space for data storage is unstable over time due to changing commercial policies, and either a server or a fee-paying service should be considered for that purpose.

\section{Interconnecting Networks for New Dissemination Schemes}

As laid out above, field archaeology relies on a set of operations that are limited by physical, technological, and human constraints, causing the process to be slowed down to a degree not compatible with the development rate of other sciences. We believe we have to change the way we perform data collection in the field and the way we present the results of archaeological fieldwork. Digital technologies can provide affordable means to reduce time and costs of these operations. In addition, increasingly cheap and portable scientific instruments allow researchers to set up field laboratories and to make steady use of these technologies during all stages of fieldwork.

Digital technologies are instrumental in the creation of digital-born data which through web-based storage and publication methods can overcome the blocks that presently affect the dissemination of primary datasets from archaeological fieldwork. The change in field practices must be accompanied by a change in publication and research behaviors (and, before that, in academic evaluation criteria). Much research is already carried out for the most part online, and this trend is only set to increase. We have to think about web-based methods of publication as the first output of archaeological research, and we advocate that the scholarly community strive to find ways for awarding academic credit for the production of digital contributions. These methods not only promise to speed up the publication pipeline, they also can expand significantly the resources available for research.

By disseminating primary datasets from archaeological fieldwork promptly in the form of structured digital data, we also can change research in scope and rhythm and as a consequence make better science. Digital technologies can provide the means to build a new architecture of data production in the field, but on this platform - that each team can design according to its funds and abilities-we need to build a new epistemological approach, one that is shaped by collaboration, networking, and openness in all its stages, what we synthetically call the NEARCHOS approach.

Acknowledgments We acknowledge the help of Giampaolo Luglio for preparing Fig. 2 and of Massimo Bozzoli for preparing Fig. 3. We are grateful to two anonymous reviewers for their constructive insights. 
Open Access This article is distributed under the terms of the Creative Commons Attribution 4.0 International License (http://creativecommons.org/licenses/by/4.0/), which permits unrestricted use, distribution, and reproduction in any medium, provided you give appropriate credit to the original author(s) and the source, provide a link to the Creative Commons license, and indicate if changes were made.

\section{References Cited}

Appadurai, A. (ed.) (1988). The Social Life of Things: Commodities in Cultural Perspective, Cambridge University Press, Cambridge.

Artioli, G. (2010). Scientific Methods and Cultural Heritage: An Introduction to the Application of Materials Science to Archaeometry and Conservation Science, Oxford University Press, Oxford.

Artioli, G., and Angelini, I. (2011). Mineralogy and archaeometry: Fatal attraction. European Journal of Mineralogy 23: 849-855.

Atici, L., Whitcher-Kansa, S., Lev-Tor, J., and Kansa, E. C. (2013). Other people's data: A demonstration of the imperative of publishing primary data. Journal of Archaeological Method and Theory 20: 663-681.

Berggren, А. (2014). Reflexive approaches in archaeology, development of. In Smith, C. (ed.), Encyclopedia of Global Archaeology, Springer, New York, pp. 6249-6257.

Berggren, A., Dell'Unto, N., Forte, M., Haddow, S., Hodder, I., Issavi, J., Lercari, N., Mazzucato, C., Mickel, A., and Taylor, J. S. (2015). Revisiting reflexive archaeology at Çatalhöyük: Integrating digital and 3D technologies at the trowel's edge. Antiquity 89: 433-448.

Bitelli, G., and Girelli, V.A. (2009). Metrical use of declassified satellite imagery for an area of archaeological interest in Turkey. Journal of Cultural Heritage 10: e35-e40.

Carver, G. (2005). Archaeological information systems (AIS): Adapting GIS to archaeological contexts. In International Congress of Cultural Heritage and New Technologies-Workshop 9 "Archäologie und Computer", Phoibos Verlag, Vienna (CD-ROM).

Cranshaw, J., and Kittur, A. (2011). The Polymath Project: Lessons from a successful online collaboration in mathematics. In Proceedings of the SIGCHI Conference on Human Factors in Computing Systems CHI '11, Association for Computing Machinery (ACM), New York, pp. $1865-1874$.

Curci, A. (2013). Working with 3D data in zooarchaeology: Potential and perspectives. Ocnus 21: 259-263.

Dallas, C. (2016). Jean-Claude Gardin on archaeological data, representation and knowledge: Implications for digital archaeology. Journal of Archaeological Method and Theory 23: 305-330.

Dell'Unto, N., Landeschi, G., Leander Touati, A. M., Dellepiane, M., Callieri, M., and Ferdani, D. (2016). Experiencing ancient buildings from a 3D GIS perspective: A case drawn from the Swedish Pompeii Project. Journal of Archaeological Method and Theory 23: pp. 73-94.

Doneus, M., and Briese, C. (2010). Airborne laser scanning in forested areas: Potential and limitations of an archaeological prospection technique. In Cowley, D. C. (ed.), Remote Sensing for Archaeological Heritage Management: Proceedings of the 11th EAC Heritage Management Symposium (Reykjavík 2010), European Archaeological Council (EAC), Brussels, pp. 59-76.

Doneus, M., and Neubauer, W. (2006). Laser scanners for 3D documentation of stratigraphic excavations. In Baltsavias, E. P., Gruen, A., Van Gool, L., and Pateraki, M. (eds.), Recording, Modeling and Visualization of Cultural Heritage: Proceedings of the International Workshop, Centro Stefano Franscini, Monte Verita, Ascona, Switzerland, May 22-27, 2005, Taylor and Francis, London, pp. 193-203.

Emberling, G., and Hanson, K. (2008). Catastrophe! The Looting and Destruction of Iraq's Past, Museum Publication No. 28, Oriental Institute, Chicago.

Fanti, F., Cau, A., Cantelli, L., Hassine, M., and Auditore, M. (2015). New information on Tataouinea hannibalis from the Early Cretaceous of Tunisia and implications for the tempo and mode of Rebbachisaurid Sauropod evolution. PLoS ONE. https://doi.org/10.1371/journal.pone.0123475.

Forte, M. (2014). 3D archaeology: New perspectives and challenges: The example of Çatalhöyük. Journal of Eastern Mediterranean Archaeology and Heritage Studies 2: 1-29. 
Forte, M., Dell'Unto, N., Issavi, J., Onsurez, L., and Lercari, N. (2012). 3D archaeology at Çatalhöyük. International Journal of Heritage in the Digital Era 1: 351-378.

Gardin, J.-C. (1956). Code pour l'analyse des cylindres orientaux, Centre d'Analyse Documentair pour l'Archéologie, Paris.

Gardin, J.-C. (1958). Four codes for the description of artifacts: An essay in archeological technique and theory. American Anthropologist 60: 335-357.

Gardin, J.-C. (1976). Code pour l'analyse des formes de poteries, Centre National de la Recherche Scientifique (CNRS), Paris.

Gardin, J.-C. (1978). Code pour l'analyse des ornements, Centre National de la Recherche Scientifique (CNRS), Paris.

Giligny, F., Djindjian, F., Costa, L., Moscati, P., and Robert, S. (eds.) (2015). CAA2014. 21st Century Archaeology. Concepts, Methods and Tools: Proceedings of the 42nd Annual Conference on Computer Applications and Quantitative Methods in Archaeology, Archaeopress, Oxford.

Hummler, M. (2014). Recording in archaeology. In Smith, C. (ed.), Encyclopedia of Global Archaeology, Springer, New York, pp. 6240-6245.

Ikeuchi, K., and Miyazaki, D. (2008). Digitally Archiving Cultural Objects, Springer, New York.

Jiménez Fernández-Palacios, B., Nex, F., and Remondino, F. (2014). ARCube-The augmented reality cube for archaeology. Archaeometry 57: 250-262.

Kansa, E. C. (2012). Openness and archaeology's information ecosystem. World Archaeology 44: 498-520.

Kansa, E. C., and Whitcher-Kansa, S. (2013). We all know that a 14 is a sheep: Data publication and professionalism in archaeological communication. Journal of Eastern Mediterranean Archaeology \& Heritage Studies 1: 88-97.

Kansa, E. C., Whitcher-Kansa, S., and Watrall, E. (eds.) (2011). Archaeology 2.0: New Approaches to Communication and Collaboration, Cotsen Digital Archaeology Series 1, Cotsen Institute of Archaeology Press, Los Angeles. Available at: http://escholarship.org/uc/item/1r6137tb.

Killick, D. (2015). The awkward adolescence of archaeological science. Journal of Archaeological Science 56: 242-247.

Kintigh, K. W., Altschul, J. H., Beaudry, M. C., Drennan, R. D., Kinzig, A. P., Kohler, T. A., Limp, W. F., Maschner, H. D., Michener, W. K., Pauketat, T. R., Peregrine, P., Sabloff, J. A., Wilkinson, T. J., Wright, H. T., and Zeder, M. A., (2014). Grand challenges for archaeology. American Antiquity 79: $5-24$.

Kintigh, K. W., Altschul, J. H., Kinzig, A. P., Limp, W. F., Michener, W. K., Sabloff, J. A., Hackett, E. J., Kohler, T. A. Ludäscher, B., and Lynch, C. A. (2015). Cultural dynamics, deep time, and data: Planning cyberinfrastructure investments for archaeology. Advances in Archaeological Practice 3(1): 1-15. https://doi.org/10.7183/2326-3768.3.1.1.

Kitchin, R., 2014. The Data Revolution: Big Data, Open Data, Data Infrastructures and Their Consequences, SAGE Publications, Thousand Oaks, CA.

Landeschi, G., Dell'Unto, N., Lundqvist, K., Ferdani, D., Campanaro, D. M., Leander Touati, A. M. (2016). 3D-GIS as a platform for visual analysis: Investigating a Pompeian house. Journal of Archaeological Science 65: 103-113.

Lasaponara, R., and Masini, N. (eds.) (2012). Satellite Remote Sensing: A New Tool for Archaeology, Springer, New York.

Londoño, W. (2014). Reflexivity in archaeology. In Smith, C. (ed.), Encyclopedia of Global Archaeology, Springer, New York, pp. 6258-6261.

Marwick, B., d'Alpoim Guedes, J., Barton, M., Bates, L. A., Baxter, M., Bevan, A., Bollwerk, A., Bocinsky, R. K., Brughmans, T., Carter, A. K., Conrad, C., Contreras, D. A., Costa, S., Crema, E. R., Daggett, A., Davies, B., Drake, L., Dye, T. S., France, P., Fullagar, R., Giusti, D., Graham, S., Harris, M. D., Hawks, J., Heath, S., Huffer, D., Kansa, E. C., Whitcher Kansa, S., Madsen, M. E., Melcher, J. Negre, J., Neiman, F. D., Opitz, R., Orton, D. C., Przystupa, P., Raviele, M., RielSalvatore, J., Riris, P., Romanowska, I., Strupler, N., Ullah, I. I., Van Vlack, H. G., Watrall, E. C., Webster, C., Wells, J., Winters, J., and Wren, C. D. (2017). Open science in archaeology. The Society for American Archaeology Archaeological Record 17(4): 8-14.

Minto, S., and Remondino, F. (2014). Online access and sharing of reality-based 3D models. SCIRES-IT SCIentific RESearch and Information Technology 4: 17-28. https://doi.org/10.2423/ i22394303v4n2p17.

Molloy, J. (2011). The open knowledge foundation: Open data means better science. PLoS Biology. https://doi.org/10.1371/journal.pbio.1001195. 
Mueller, T. (2016). How tomb raiders are stealing our history. National Geographic 229: 58-81.

Pollard, A. M., and Heron, C. (eds.) (2008). Archaeological Chemistry, 2nd ed., Royal Society of Chemistry, Cambridge.

Roosevelt, C. H., Cobb, P., Moss, E., Olson, B. R., and Ünlüsoy, S. (2015). Excavation is destruction digitization: Advances in archaeological practice. Journal of Field Archaeology 40: 325-346.

Rosner, D., Roccetti, M., and Marfia, G. (2014). The digitization of cultural practices. Communications of the Association for Computing Machinery 57 6: 82-87. https://doi.org/10.1145/2602695.2602701.

Salomoni, P., Prandi, C., Roccetti, M., Casanova, L., Marchetti, L., and Marfia, G. (2017). Diegetic user interfaces for virtual environments with HMDs: A user experience study with oculus rift. Journal on Multimodal User Interfaces 11: 173-184.

Snow, D., Gahegan, M., Giles, C., Hirth, K., Milner, G., Mitra, P., and Wang, J. (2006). Information science, cybertools and archaeology. Science 311: 958-959.

Smith, M. E., Feinman, G. M., Drennan, R. D., Earle, T. K., and Morris, I. (2012). Archaeology as a social science. Proceedings of the National Academy of Sciences USA 109: 7617-7621.

Smith, M. E. (2014). Do publishing trends collide with the grand challenges of archaeology? The SAA Archaeological Record 14: 5.

Smith, M. E. (2017). Social science and archaeological inquiry. Antiquity 91: 520-528.

Ur, J. (2013). Spying on the past: Declassified intelligence satellite photographs and Near Eastern landscapes. Near Eastern Archaeology 76: 28-36.

Weiner, S. (2010). Microarchaeology: Beyond the Visible Archaeological Record, Cambridge University Press, Cambridge.

Wilson, A. T., and Edwards, B. (eds.) (2015). Open Source Archaeology: Ethics and Practice, De Gruyter, Berlin. Available at: http://www.degruyter.com/view/product/460080.

Wilson, C. A., Davidson, D. A., and Cresser, M. S. (2008). Multi-element soil analysis: An assessment of its potential as an aid to archaeological interpretation. Journal of Archaeological Science 35: $412-424$.

\section{Bibliography of Recent Literature}

Albarella, U. (ed.) (2001). Environmental Archaeology: Meaning and Purpose, Kluwer Academic Publishers, Dordrecht.

Aspöck, E., and Masur, A. (2015). Digitizing early farming cultures customizing the Arches Heritage Inventory \& Management System. In Proceedings of Digital Heritage International Congress 2015, 28. Sept.-2. Oct., Granada, Spain. IEEE Press, New York, pp. 463-464. https://doi.org/10.1109/ DigitalHeritage.2015.7419549.

Bitelli, G., Girardi, F., and Girelli, V.A. (2014). Digital enhancement of the 3D scan of Suhi I's stele from Karkemish. Orientalia 83: 154-161.

Curci, A., Urcia, A., Lippiello, L., and Gatto, M. C. (2012). Using digital technologies to document rock art in the Aswan-Kom Ombo region (Egypt). Sahara 23: 75-86.

De Reu, J., De Smedt, P., Herremans, D., Van Meirvenne, M., Laloo, P., and De Clercq, W. (2014). On introducing an image-based 3D reconstruction method in archaeological excavation practice. Journal of Archaeological Science 41: 251-262.

Forte, M., and Pietroni, E. (2009). 3D collaborative environments in archaeology: Experiencing the reconstruction of the past. International Journal of Architectural Computing 7: 58-76. https://doi. org/10.1260/147807709788549349.

Grosman, L., Karasik, A., Harush, O., and Smilanksy, U. (2014). Archaeology in three dimensions: Computer-based methods in archaeological research. Journal of Eastern Mediterranean Archaeology and Heritage Studies 2: 48-64.

Hunt, A. M., and Speakman, R. J. (2015). Portable XRF analysis of archaeological sediments and ceramics. Journal of Archaeological Science 53: 626-638.

Ioannides, M., Hadjiprocopis, N., Doulamis, A., Doulamis, E., Protopapadakis, K., and Makantasis, P. (2013). Online 4d reconstruction using multi-images available under Open Access. ISPRS Annals of Photogrammetry, Remote Sensing and Spatial Information Sciences 1: 169-174.

Martinón-Torres, M., and Rehren, T. (eds.) (2008). Archaeology, History and Science: Integrating Approaches to Ancient Materials, Left Coast Press, Walnut Creek, CA. 
Matsumoto, G. (2009). Fill in the gap between theory and practice: Making a GIS-based digital map of Pachacamac. In Wilkins, J., and Anderson, K. (eds). Tools of the Trade: Methods, Techniques and Innovative Approaches in Archaeology, University of Calgary Press, Calgary, pp. 217-235.

Pearce, N., Weller, M., Scanlon, E., and Ashleigh, M. (2010). Digital scholarship considered: How new technologies could transform academic work. in education 16: 33-44.

Rathje, W., Shanks, M., and Witmore, C. (eds.) (2013). Archaeology in the Making: Conversations through a Discipline, Routledge, London.

Redman, C. L., Grove, J. M., and Kuby, L. H. (2004). Integrating social science into the long-term ecological research (LTER) network: Social dimensions of ecological change and ecological dimensions of social change. Ecosystems 7: 161-171.

Remondino, F., and Campana, S. (2014). 3D Recording and Modelling in Archaeology and Cultural Heritage: Theory and Best Practices, BAR International Series S2598, Archaeopress, Oxford.

Rosenbauer, C., Rutishauser, S., Trachsel, T., Kilchör, F., and Wittlin, E. (2013). The virtual Cilicia project: How to use Google Earth as a visualization environment in an archaeological context. In Sieck, J. (ed.), Kultur und Informatik: Visual Worlds \& Interactive Spaces, Werner Hülsbusch, Berlin, pp. 255-264.

Tringham, R. (2012). Households through a digital lens. In Parker, B. J., and Foster, C. P. (eds.), New Perspectives on Household Archaeology, Eisenbrauns, Winona Lake, WI, pp. 81-122.

Vincent, M. L., Kuester, F., and Levy, T. E. (2014). OpenDig: Contextualizing the past from the field to the web. Mediterranean Archaeology and Archaeometry 14: 109-116. 